\title{
HFE gene mutations in coronary atherothrombotic disease
}

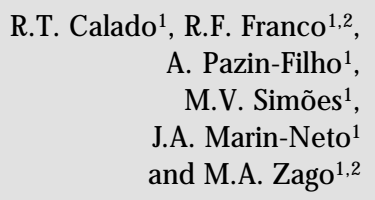

\author{
${ }^{1}$ Departamento de Clínica Médica, Faculdade de M edicina de Ribeirão Preto, \\ Universidade de São Paulo, Ribeirão Preto, SP, Brasil \\ ${ }^{2}$ Fundação Hemocentro de Ribeirão Preto, Ribeirão Preto, SP, Brasil
}

\section{Correspondence}

R.F. Franco

Laboratório de Hematologia

Departamento de Clínica Médica

FMRP, USP

Av. Bandeirantes, 3900

14048-900 Ribeirão Preto, SP

Brasil

Fax: + 55-16-633-1144

E-mail: rffranco@ netsite.com.br

Research partially supported by FAPESP (No. 98/02821-0) and FUNDHERP.

Received April 9, 1999

Accepted January 18, 2000

\section{Abstract}

Although iron can catalyze the production of free radicals involved in LDL lipid peroxidation, the contribution of iron overload to atherosclerosis remains controversial. The description of two mutations in the HFE gene (Cys282Tyr and His63Asp) related to hereditary hemochromatosis provides an opportunity to address the question of the association between iron overload and atherosclerosis. We investigated the prevalence of HFE mutations in 160 survivors of myocardial infarction with angiographically demonstrated severe coronary atherosclerotic disease, and in 160 age-, gender- and race-matched healthy control subjects. PCR amplification of genomic DNA followed by $R s a \mathrm{I}$ and $\mathrm{BclI}$ restriction enzyme digestion was used to determine the genotypes. The frequency of the mutant Cys282Tyr allele was identical among patients and controls (0.022; carrier frequency, 4.4\%), whereas the mutant His63Asp allele had a frequency of 0.143 (carrier frequency, 27.5\%) in controls and of 0.134 (carrier frequency, 24.5\%) in patients. Compound heterozygotes were found in 2 of $160(1.2 \%)$ controls and in 1 of $160(0.6 \%)$ patients. The finding of a similar prevalence of Cys282Tyr and His63Asp mutations in the HFE gene among controls and patients with coronary atherothrombotic disease, indirectly questions the possibility of an association between hereditary hemochromatosis and atherosclerosis.

\section{Introduction}

Based on the lower rate of coronary atherosclerotic disease (CAD) observed in premenopausal women compared to men and postmenopausal women and on the difference in CAD incidence between developed and underdeveloped countries, in 1981, Sullivan (1) hypothesized that higher iron stores could be a risk factor for CAD. In this sense, many investigators have studied the contribution of iron overload to the pathogenesis of atherosclerosis. In addition, with

\section{Key words}

- Hemochromatosis

- HFE gene

- Atherosclerosis

- Myocardial infarction

- Risk factor the demonstration that iron catalyzes the synthesis of oxygen-reactive products (2), it has been also proposed that iron could play a role in LDL lipid peroxidation $(3,4)$, an early step in atherogenesis (5). To support this hypothesis, it has been experimentally observed that iron overload contributes to atherogenesis in rabbits (6); however, other investigators demonstrated that, in the same animal model, iron overload causes a decrease in plasma cholesterol levels as well as in the formation of lesions in the aortic arch (7). Similarly, whereas some epidemiological 
studies (8-11) have found a positive association between CAD and clinical markers of iron overload, other reports have found either a negative association (12) or none at all $(13,14)$. Thus, the "iron hypothesis" remains controversial.

Hereditary hemochromatosis $(\mathrm{HH})$ is an autosomal recessive genetic disease of iron regulation associated with iron overload and failure of several organs $(15,16)$. The molecular bases of $\mathrm{HH}$ were elucidated in 1996 after the positional cloning of the involved gene, currently designated HFE (formerly HLA-H) (17). The HFE gene has been sequenced, and two missense point mutations have been identified: a substitution of tyrosine for cysteine at amino acid position 282 of the HFE protein (Cys282Tyr), and a substitution of aspartic acid for histidine at amino acid position 63 (His63Asp) (17). Cys282Tyr is strongly related to the disease, but the clinical significance of the His63Asp mutant in $\mathrm{HH}$ remains to be determined, although it seems to increase the risk for $\mathrm{HH}$ in the compound heterozygous state with Cys282Tyr (18). In addition, carriers of these mutations tend to present higher iron deposits (19).

The analysis of HFE mutations in patients with atherosclerotic disease represents a valuable opportunity to determine the specific role of $\mathrm{HH}$ in atherosclerosis. In this respect, it should be emphasized that although $\mathrm{HH}$ is an autosomal recessive disorder, heterozygotes usually exhibit evidence of iron accumulation that might result in increased predisposition to atherosclerosis. If indeed hemochromatosis contributes to atherogenesis, a higher prevalence of $\mathrm{HH}-$ related mutations in patients suffering from atherosclerotic disease in comparison to healthy individuals is predicted. Hence, the prevalence of HFE mutations in selected patients with objective diagnosis of coronary atherothrombosis in comparison to healthy controls was evaluated in the present study.

\section{Subjects and Methods}

\section{Patients and controls}

A total of 160 unrelated and relatively young individuals (124 men; mean age, 42 years; range, 25-55 years; and 36 women; mean age, 46 years; range, $30-55$ years) with a diagnosis of acute myocardial infarction (MI) and angiographically proven CAD constituted the patient study group. MI was diagnosed on the basis of clinical, enzymatic and electrocardiographic criteria. At least two of the following criteria were necessary to arrive at this diagnosis: typical chest pain (longer than $30 \mathrm{~min}$ ), an increase in creatine kinase of more than twice the baseline level, and characteristic electrocardiographic changes in two or more adjacent leads. Included were patients submitted to coronary angiography, which demonstrated stenosis of $50 \%$ or higher in a major artery. While the samples from patients were being collected, 160 unrelated subjects (mostly blood donor candidates at the local Blood Center) without a personal history of arterial disease or MI were selected as controls. Controls were enrolled before the first blood donation. Each case was matched to a control for gender, age ( \pm 4 years) and race. Both patients and controls came from the same geographic region, i.e., the city of Ribeirão Preto, State of São Paulo, Southeastern Brazil. All individuals enrolled gave their consent to participate in this study, which was approved by the Institutional Ethics Committee. Data regarding classical risk factors for CAD and MI were obtained by reviewing records and interviewing the subjects included in the study. Subjects were classified as Whites, Blacks or Mulattoes on the basis of phenotype characteristics.

\section{Mutation analysis}

Peripheral blood was collected and genomic DNA extracted from mononuclear 
leukocytes by conventional methods (20). For identification of the Cys282Tyr mutation, the following primers were used: $5^{\prime}$ CAA GTG CCT CCT TTG GTG AAG GTG ACA CAT - 3' and 5' - CTC AGG CAC TCC TCT CAA CC - 3'. For identification of the His63Asp mutation, the following primers were used: 5' - ACA TGG TTA AGG CCT GTT GC - 3' and 5' - CTT GCT GTG GTT GTG ATT TTC C - 3' (21). RsaI (Cys282Tyr analysis) and $B c l$ I (His63Asp analysis) restriction enzyme digestion was employed after PCR genomic amplification to determine the HFE genotypes.

\section{Statistical analysis}

Differences of allele frequencies of each mutation in controls and patients were analyzed for statistical significance by the $\chi^{2}$ test. Odds ratios (OR) and $95 \%$ confidence intervals (CI 95) were calculated using standard methods (22).

\section{Results}

Table 1 lists relevant general characteristics of the patient and control groups. As expected, major risk factors for atherosclerotic disease were present in most cases and were rarer among subjects from the control group.

The mutant Cys282Tyr allele was found in the heterozygous state in 7 of 160 controls (allele frequency, 0.022; carrier frequency, $4.4 \%$ ) and in 7 of 160 patients with MI (allele frequency, 0.022; carrier frequency, 4.4\%; Table 2). These data yielded an OR for MI related to the Cys282Tyr mutation of 1.0 (CI 95: 0.34-2.91). No homozygotes for the Cys282Tyr mutation were found in controls or patients (Table 3). The His63Asp mutation was detected in 44 of 160 controls (allele frequency, 0.143; carrier frequency, $27.5 \%$ ) and in 39 patients (allele frequency, 0.134 ; carrier frequency, $24.5 \%$; Table 2). These data yielded an OR for MI related to the His63Asp mutation of 0.8 (CI 95: 0.511.40). Two homozygotes and 42 heterozygotes for the His63Asp mutation were detected among the controls, whereas 4 homozygotes and 35 heterozygotes were de-

Table 1 - General characteristics of myocardial infarction (MI) survivors with angiographically demonstrated severe atherosclerosis and of control subjects.

*Physician's diagnosis and/or drug-treatment. \#Body mass index $\geq 30 \mathrm{~kg} / \mathrm{m}^{2}$. CAD, Coronary atherosclerotic disease.

\begin{tabular}{lcc}
\hline Variable & $\begin{array}{c}\text { Patients } \\
(\mathrm{N}=160)\end{array}$ & $\begin{array}{c}\text { Controls } \\
(\mathrm{N}=160)\end{array}$ \\
\hline Males & $124(77.5 \%)$ & $124(77.5 \%)$ \\
Whites & $132(82.5 \%)$ & $132(82.5 \%)$ \\
Blacks and & $28(17.5 \%)$ & $28(17.5 \%)$ \\
$\quad$ Mulattoes & & \\
Mean age (range) & $43(25-55)$ & $42(22-55)$ \\
Family history of & $52(32.5 \%)$ & $24(15 \%)$ \\
$\quad$ CAD/MI & & \\
$\begin{array}{l}\text { Dyslipidemia* } \\
\text { Hypertension* }\end{array}$ & $52(32.5 \%)$ & $5(3.1 \%)$ \\
Diabetes mellitus* & $24(15 \%)$ & $4(2.5 \%)$ \\
Current smoking & $107(66.9 \%)$ & $32(20 \%)$ \\
Obesity & $32(20 \%)$ & $13(8.1 \%)$
\end{tabular}

Table 2 - Allele frequencies of HFE mutations in controls and in patients with myocardial infarction (MI).

Number of mutated chromosomes/number of chromosomes analyzed; allele frequencies are given in parentheses. None of the differences reached statistical significance ( $\mathrm{P}>0.05)$. OR: Odds ratio for $\mathrm{MI}$; $\mathrm{Cl} 95$ : $95 \%$ confidence interval.

\begin{tabular}{lrrr}
\hline Mutation & \multicolumn{1}{c}{ Patients } & \multicolumn{1}{c}{ Controls } & OR (Cl 95) \\
\hline Cys282Tyr & $7 / 320(0.022)$ & $7 / 320(0.022)$ & $1.0(0.34-2.91)$ \\
His63Asp & $43 / 320(0.134)$ & $46 / 320(0.143)$ & $0.8(0.51-1.40)$
\end{tabular}

Table 3 - Hereditary hemochromatosis genotypes for controls and for myocardial infarction patients.

C282Y and H63D indicate Cys282Tyr and His63Asp, respectively. None of the differences shown in this table was statistically significant $(P>0.05)$.

\begin{tabular}{lclllll}
\hline Genotype $\mathrm{C} 282 \mathrm{Y}+/+$ & $\mathrm{C} 282 \mathrm{Y}+/-$ & $\mathrm{C} 282 \mathrm{Y}-$ & $\mathrm{C} 282 \mathrm{Y}-$ & $\mathrm{C} 282 \mathrm{Y}+/-$ & $\mathrm{C} 282 \mathrm{Y}-$ \\
& $\mathrm{H} 63 \mathrm{D}--$ & $\mathrm{H} 63 \mathrm{D}-$ & $\mathrm{H} 63 \mathrm{D}+/+$ & $\mathrm{H} 63 \mathrm{D}+/-$ & $\mathrm{H} 63 \mathrm{D}+/-$ & H63D -/- \\
\hline Controls & $0(0)$ & $5(3.1 \%)$ & $2(1.2 \%)$ & $40(25 \%)$ & $2(1.2 \%)$ & $111(69.4 \%)$ \\
Patients & $0(0)$ & $6(3.7 \%)$ & $4(2.5 \%)$ & $34(21.3 \%)$ & $1(0.6 \%)$ & $115(71.9 \%)$
\end{tabular}


tected among the patients (Table 3). Compound heterozygosity for both mutations was observed in 2 controls (1.2\%), whereas only one patient carried both mutations $(0.6 \%)$. Separate analysis for White subjects (who corresponded to the majority of the subjects) did not alter the results (data not shown in tables).

\section{Discussion}

Since Sullivan (1) raised the hypothesis that iron overload could be a risk factor for CAD, many investigators have tested this possibility, but no definitive conclusion has been reached due to conflicting results (3,4,6-14,23-25). Since the occurrence of HFE gene mutations associated with $\mathrm{HH}$ provides a valuable opportunity to test indirectly whether iron overload plays a role in atherosclerosis, the prevalence of these two mutations in patients with coronary atherothrombosis and in healthy controls was determined in the present study.

The prevalence of the Cys282Tyr mutation in healthy Brazilian subjects (carrier frequency, $4.4 \%$ ) is lower than that observed in Europeans, among whom this mutation is most prevalent (21). In contrast, it is more prevalent in Brazilians than in other American populations such as Mexicans, Jamaicans and Colombians (21). These findings can be explained by the different ethnic composition of these peoples. The Cys282Tyr mutation is believed to have arisen approximately 60 to 70 generations in the past and is highly prevalent among Europeans, but rarer among Africans $(16,18,19)$. Therefore, a lower prevalence of the Cys282Tyr mutation among Brazilians in comparison with Europeans is expected on the basis of the miscegenation of Whites and Blacks, and indeed the prevalence found in the present investigation agrees with a previous report on the frequency of Cys282Tyr among Brazilians (26). The His63Asp mutation was found to be highly prevalent among Brazil- ians (carrier frequency, 27.5\%), with a frequency similar to that observed among white Europeans. In fact, the His63Asp mutation has been identified in populations of different ethnic origins and probably is an older mutation (21). Hence, the finding of a high prevalence of this mutation in the Brazilian population is also reasonable, since its prevalence is less affected by racial admixture. Of note, since ethnicity may influence the comparability of patients and controls in casecontrol studies, the control and the disease groups of this study were matched taking into account also the ethnic background of the subjects.

The mutant Cys282Tyr and His63Asp alleles had an identical frequency in controls and CAD patients, suggesting that mutations of the HFE gene have no significant effect on atherosclerosis. Although previous reports on the association between iron stores and atherosclerosis have yielded discrepant results, it should be noted that epidemiological studies may be subjected to biases from different environmental factors $(24,25)$. For instance, the observation that postmenopausal women receiving estrogen replacement therapy have a risk for CAD similar to that of premenopausal women (27) suggested that the determining factor for increased risk after menopause is a reduction in estrogen levels, rather than iron overload, as it had been previously supposed (1). In fact, in several of the epidemiological studies designed to assess the possible relation between body iron stores and atherosclerotic disease, no association was found, and even an inverse association was suggested in one of them (12). Moreover, supporting our findings is the recent demonstration that, in rabbits, iron overload decreases plasma cholesterol levels and the formation of an aortic arch lesion, suggesting that excess iron does not contribute to atherosclerosis (7). It has also been observed that, although iron can mediate oxidant injury to endothelial cells, the damage may be attenuated by iron chela- 
tors such as ferritin (28).

Recently, we also analyzed the prevalence of HH-related mutations in patients with premature atherosclerotic disease from the Netherlands. The results for the Dutch population were similar to those obtained in the present study insofar as they did not support genetic hemochromatosis as a major risk factor for atherosclerosis (29). In this respect, it should be noted that the recently described polymorphism in intron 4 does not affect our results (30), since we did not find a mutant homozygous for the Cys282Tyr mutation. However, it should be emphasized that, although a higher prevalence of the HFE mutations was not observed among CAD patients in comparison with healthy subjects in the present study, the possibility that iron may contribute to atherosclerosis cannot be completely ruled out. Firstly, we analyzed a population for which parameters of evaluation of body iron stores (such as transferrin saturation or serum ferritin levels) were not available, and in fact such analysis is beyond the scope of our study. Therefore, our conclusions are based on the absence of a significant association between specific gene variations and atherosclerosis, and do not take into account the possibility that a certain degree of iron deficiency may have diminished iron accumulation among carriers of the HH-related mutations and its impact as a putative atherogenic factor. In fact, our data do not exclude the possibility of an association between $\mathrm{HH}$ and atherosclerosis in other populations. Secondly, our study deals with the analysis of HFE mutations in women and men, and the former are known to have increased iron loss (due to menstruation and pregnancy) which can also minimize the effect of the HFE mutations on iron accumulation. On the other hand, women were only a minority of the individuals analyzed, cases and controls were matched for gender, and separate analysis of data among males did not alter our results (data not shown). In addition, we investigated only individuals less than 55 years of age, and our results should not be extrapolated to older HFE carriers, in whom a more evident iron accumulation may be present. Moreover, an association with recurrent cardiovascular events was not explored in our study. Finally, it could also be hypothesized that iron is mainly stored in parenchymal tissues in $\mathrm{HH}$, and therefore iron deposits in the macrophage system (which could contribute to foam cell formation and atherosclerosis progression) are not increased in carriers of the HFE mutations. Under any of these circumstances, this study suggests that screening of $\mathrm{HH}$ mutations among patients with CAD and MI does not seem to be justified in our population.

To sum up, we found a similar prevalence of the HFE gene mutations in relatively young patients with CAD and controls. We conclude that HFE mutations related to $\mathrm{HH}$ are unlikely to be major genetic risk factors for coronary atherothrombotic disease in the Brazilian population.

\section{Acknowledgments}

The authors are indebted to Mrs. Marli $\mathrm{H}$. Tavella and Mrs. Amélia G. Araújo for excellent technical assistance.

\section{References}

1. Sullivan J L (1981). Iron and the sex difference in the heart disease risk. Lancet, 307: 1293-1294.

2. McCord J M (1998). Iron, free radicals, and oxidative injury. Seminars in Hematology, 35: 5-12.
3. Corti MC, Gaziano M \& Hennekens $\mathrm{CH}$ (1997). Iron status and risk of cardiovascular disease. Annals of Epidemiology, 7: 62-68.

4. Meyers DG (1996). The iron hypothesis does iron cause atherosclerosis? Clinical
Cardiology, 19: 925-929.

5. Diaz MN, Frei B, Vita J A \& Keaney J r J F (1997). Antioxidants and atherosclerotic heart disease. New England J ournal of Medicine, 337: 408-417.

6. Araújo J A, Romano EL, Brito BE, Parthe 
V, Romano M, Bracho M, Montano RF \& Cardier J (1995). Iron overload augments the development of atherosclerotic lesions in rabbits. Arteriosclerosis, Thrombosis, and Vascular Biology, 15: 11721180.

7. Dabbagh AJ , Shwaery GT, Keaney J rJ F \& Frei B (1997). Effect of iron overload and iron deficiency on atherosclerosis in the hypercholesterolemic rabbit. Arteriosclerosis, Thrombosis, and Vascular Biology, 17: 2638-2645.

8. Lauffer RB (1990). Iron stores and the international variation in the mortality from coronary artery disease. Medical Hypotheses, 35: 96-102.

9. Salonen JT, Nyyssönen $K$, Korpela $H$, Tuomilehto J , Seppänen R \& Salonen R (1992). High stored iron levels are associated with excess risk of myocardial infarction in eastern Finnish men. Circulation, 86: 803-811.

10. Morrison HI, Semenciw RM, Mao $Y \&$ Wigle DT (1994). Serum iron and risk of fatal acute myocardial infarction. Epidemiology, 5: 243-246.

11. Kiechl S, Willeit J, Egger G, Poewe W \& Oberhollenzer $F$ (1997). Body iron stores and the risk of carotid atherosclerosis. Circulation, 96: 3300-3307.

12. Sempos CT, Looker AC, Gillium RF \& Maruk DM (1994). Body iron stores and the risk of coronary heart disease. New England J ournal of Medicine, 330: 11191124.

13. Stampfer MJ , Grodstein F, Rosemberg I, Willett W \& Hennekens C (1993). A prospective study of plasma ferritin and risk of myocardial infarction in US physicians. Circulation, 87: 688 (Abstract).

14. Reunanen $A$, Takkunen $H$, Knekt $P$, Seppänen R \& Aromaa A (1995). Body iron states, dietary iron intake and coronary heart disease mortality. J ournal of Internal Medicine, 238: 223-230.
15. Bothwell TH \& MacPhail P (1998). Hereditary hemochromatosis: etiologic, pathologic, and clinical aspects. Seminars in Hematology, 35: 55-71.

16. Andrews NC \& LevyJ E (1998). Iron is hot: an update on the pathophysiology of hemochromatosis. Blood, 92: 1845-1851.

17. Feder J N, Gnirke A, Thomas W, Tsuchihashi Z, Ruddy DA, Basava A, Dormishian $F$, Domingo J $r$, Ellis $M C$, Fullan A, Hinton LM, J ones NL, Kimmel BE, Kronmal GS, Lauer P, Lee VK, Loeb DB, Mapa FA, McClelland E, Meyer NC, Mintier GA, Moeller N, Moore T, M orikang $E$, Prass CE, Quintana L, Starnes SM, Schatzman RC, Brunke KN, Drayna DT, Risch NJ , Bacon BR \& Wolff RK (1996). A novel MHC class I-like gene is mutated in patients with hereditary haemochromatosis. Nature Genetics, 13: 399-407.

18. Beutler E, Gelbart T, West C, Lee P, Adams M, Blackstone R, Pockros P, Kosty $M$, Venditti $C P$, Phatak PD, Seese NK, Chorney KA, Ten Elshof AE, Gerhard GS $\&$ Chorney M (1996). Mutation analysis in hereditary hemochromatosis. Blood Cells, Molecules, and Diseases, 22: 187-194.

19. Garry PJ , Montoya GD, Baumgartner RN, Liang HC, Williams TM \& Brodie SG (1997). Impact of HLA-H mutations on iron stores in healthy elderly men and women. Blood Cells, Molecules, and Diseases, 23: 277-287.

20. Saiki RK, Gelfand DH, Stoffel S, Scharf SJ , Higushi R, Horn GT, Mullis KB \& Erlich HA (1988). Primer-directed enzymatic amplification of DNA with a thermostable DNA polymerase. Science, 239: 487-491.

21. Merryweather-Clarke AT, Pointon JJ, Shearman J D \& Robson KJ H (1997). Global prevalence of putative haemochromatosis mutations. J ournal of Medical Genetics, 34: 275-278

22. Woolf B (1955). On estimating the relation between blood group and disease.
American J ournal of Human Genetics, 19: 251.

23. Gillum RF (1997). Body iron stores and atherosclerosis. Circulation, 96: 32613263.

24. Burt MJ , Halliday J W \& Powell LW (1993) Iron and coronary heart disease. British Medical J ournal, 307: 575-576.

25. Ascherio A \& Willett WC (1994). Are body iron stores related to the risk of coronary heart disease? New England J ournal of Medicine, 330: 1152-1153.

26. Annichino-Bizzachi J M, Saad STO, Arruda VR, Siqueira LH, Chiaparini LC \& Mansur AP (1997). Mutação CYS282TYR relacionada à hemocromatose em pacientes com infarto do miocárdio. Anais do XVI Congresso Nacional do Colégio Brasileiro de Hematologia, Belo Horizonte, P148 (Abstract)

27. Stampfer MJ, Colditz GA, Willett WC Manson JE, Rosner B, Speizer FE \& Hennekens CH (1991). Postmenopausal estrogen therapy and cardiovascular disease. Ten-year follow-up from the Nurses' Health Study. New England J ournal of Medicine, 325: 756-762.

28. J uckett MB, Balla J, Balla G, J essurun J J acob HS \& Vercellotti GM (1995). Ferritin protects endothelial cells from oxidized low density lipoprotein in vitro. American J ournal of Pathology, 147: 782-789.

29. Franco RF, Zago MA, Trip MD, ten Cate $\mathrm{H}$, van den Ende $A$, Prins $M H$, Kastelein J J P \& Reitsma PH (1998). Prevalence of hereditary haemochromatosis in premature atherosclerotic vascular disease. British J ournal of Haematology, 102: 11721175 .

30. J effrey GP, Chakrabarti S, Hegele RA \& Adams PC (1999). Polymorphism in intron 4 of HFE may cause overestimation of $\mathrm{C} 282 \mathrm{Y}$ homozygote prevalence in haemochromatosis. Nature Genetics, 22: 325326. 